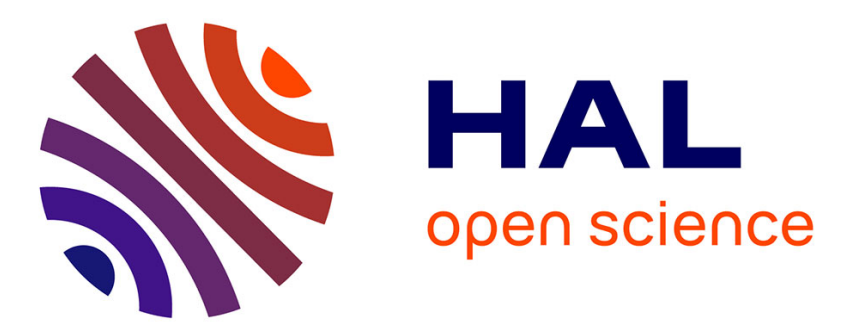

\title{
Biomaterials porosity determined by fractal dimensions, succolarity and lacunarity on microcomputed tomographic images.
}

Mambaye N'Diaye, Cristinel Degeratu, Jean-Michel Bouler, Daniel Chappard

\section{- To cite this version:}

Mambaye N'Diaye, Cristinel Degeratu, Jean-Michel Bouler, Daniel Chappard. Biomaterials porosity determined by fractal dimensions, succolarity and lacunarity on microcomputed tomographic images.. Materials Science and Engineering: C, 2013, 33, pp.2025-2030. 10.1016/j.msec.2013.01.020 . hal00829808

\section{HAL Id: hal-00829808 \\ https://hal.science/hal-00829808}

Submitted on 3 Jun 2013

HAL is a multi-disciplinary open access archive for the deposit and dissemination of scientific research documents, whether they are published or not. The documents may come from teaching and research institutions in France or abroad, or from public or private research centers.
L'archive ouverte pluridisciplinaire HAL, est destinée au dépôt et à la diffusion de documents scientifiques de niveau recherche, publiés ou non, émanant des établissements d'enseignement et de recherche français ou étrangers, des laboratoires publics ou privés. 


\title{
Biomaterials porosity determined by fractal dimensions, succolarity and lacunarity on microcomputed tomographic images.
}

\author{
Mambaye N'DIAYE ${ }^{\text {a }}$, Cristinel DEGERATU ${ }^{\text {a,b }}$, Jean-Michel BOULER ${ }^{\text {c }}$, Daniel CHAPPARD ${ }^{\text {a }}$ \\ a LUNAM Université, GEROM Groupe Etudes Remodelage Osseux et bioMatériaux - LHEA, IRIS-IBS Institut de Biologie en Santé, CHU d'Angers, 49933 \\ ANGERS Cedex -FRANCE. \\ b University Politehnica of Bucharest, Faculty of Applied Chemistry and Materials Science, Department of Bioresources and Polymer Science, Calea Victoriei \\ 149, 010072, sector 1, Bucharest, Romania \\ c Inserm UMR 791 - LIOAD, University of Nantes - 44000 Nantes - FRANCE. \\ Corresponding author: Daniel CHAPPARD, e-mail: daniel.chappard@ univ-angers.fr
}

Key words: porosity; connectivity; fractal dimension; lacunarity; succolarity.

\section{ABSTRACT}

Porous structures are becoming more and more important in biology and material science because it helps in reducing the density of the grafted material. For biomaterials, porosity also increases the accessibility of cells and vessels inside the grafted area. However, descriptors of porosity are scanty. We have used a series of biomaterials with different types of porosity (created by various porogens: fibers, beads ...). Blocks were studied by microcomputed tomography for the measurement of 3D porosity. 2D sections were re-sliced to analyze the microarchitecture of the pores and were transferred to image analysis programs: star volumes, interconnectivity index, Minkowski-Bouligand and Kolmogorov fractal dimensions were determined. Lacunarity and succolarity, two recently described fractal dimensions, were also computed. These parameters provided a precise description of porosity and pores' characteristics. Non-linear relationships were found between several descriptors e.g. succolarity and star volume of the material. A linear correlation was found between lacunarity and succolarity. These techniques appear suitable in the study of biomaterials usable as bone substitutes.

Materials Science and Engineering: C Volume 33, 2013, Pages 2025-2030.

http://www.sciencedirect.com/science/article/pii/S0928493113000337

http://www.ncbi.nlm.nih.gov/pubmed/?term=Biomaterial+porosity+determined+by+fractal+dimensions $\% 2 \mathrm{C}+$ succol arity+and+lacunarity+on+microcomputed+tomographic+images 


\section{Introduction}

Biomaterials are used in orthopedic, maxilla-facial and odontology surgeries to fill localized bone loss. They are the support of osteoconduction which allows osteoblasts (bone forming cells) to synthesize new bone on their surface [1]. Biomaterials come in direct contact with cells and biological fluids [2]. They are exposed to biochemical attacks but biomechanical strains can also influence their behavior when placed in weight-bearing sites. The tissue bioreaction of a material depends on its chemical composition but also on other factors such as its 3D arrangement, i.e. its shape or microarchitecture [3]. For a given bone biomaterial, its amount, microarchitecture, degree of anisotropy, porosity (connected or not), are significant factors to be considered. Porosity is a property which depicts the amount of void cavities in a given material. The parameter is known to correlate with mechanical properties [4-6]. There are numerous methods to determine porosity based on physical methods (e.g. mercury injection porosity, Archimede's principle, Helium pycnometry). However, these methodologies are often destructive, require techniques which are not at disposal in biological laboratories and do not provide information on the spatial distribution of the pores. X-ray microcomputed tomography (microCT) was recently described as an interesting technique when applied to porous biomaterials [7-10]. Most microCT allow the quantitative analysis of the material volume and also provide some $2 \mathrm{D}$ and $3 \mathrm{D}$ microarchitectural descriptors. However, the complexity and uniformity of the material distribution within the volume of interest are poorly investigated. MicroCT offers the advantage of been nondestructive for samples [7, 9-11]. However, it provides a limited number of parameters concerned with porosity and algorithms used by the different systems on the market are not fully validated [11]. The use of other methods for determining microarchitectural descriptors of porosity can be obtained on 2D sections obtained after re-slicing the 3D models.

Fractal geometry is well adapted to describe complexity and powerful parameters can quantify and discriminate the irregularity of material samples [12]. Several methods for determining fractal dimension exist: box counting dimension [13], mass radius [14], Hausdorff dimension [15]... These fractal dimensions are measurements of the irregularity of a given material but do not take into account its uniformity of repartition in the referent space. Recently, new fractal parameters (lacunarity and succolarity) have been reported to improve the description of a fractal porous object [14, 16]. Lacunarity is influenced by the variation of the pores in a given structure; a low lacunarity reflects homogeneity while a high lacunarity is an indicator of heterogeneity. Lacunarity was used as a measure of the complexity of objects: microcalcifications on mammograms [17], lung texture [18] neuronal complexity [14] cutaneous naevi [19] or trabecular bone [20].

Succolarity was defined by Mandelbrot as a parameter which informs about connectivity and inter communication [12]. Succolarity can be represented as the degree of penetration of a liquid inside an object according to the direction of entry of the liquid [16, 21]. Porosity, fractal dimension, lacunarity and succolarity are likely to be complementary parameters because objects having same porosity and/or fractal dimension can differ by the connectedness of their pores or the presence of connecting channels. Succolarity was found useful to evaluate the blood flow in atheromatous carotids [16] and the complexity of DNA olfactory receptors [22].

In the present study, we have evaluated different types of porous biomaterials in order to get a precise description of their microarchitecture. Biomaterials were analyzed by microCT which allowed the measurement of the 3D volume and basic parameters linked with porosity. Fractal dimensions, lacunarity and succolarity were also determined in order to characterize the ability of biological fluids to invade the biomaterial. Other classical descriptors of 2D connectivity and pore size available in Euclidean geometry were used in parallel.

\section{Material and Methods}

\subsection{Sample preparation}

Eight types of porous biomaterials were prepared with an interconnected or non-connected porosity. For each series, 3 samples were prepared.

2.1.1- Porous blocks of methacrylic polymer. 

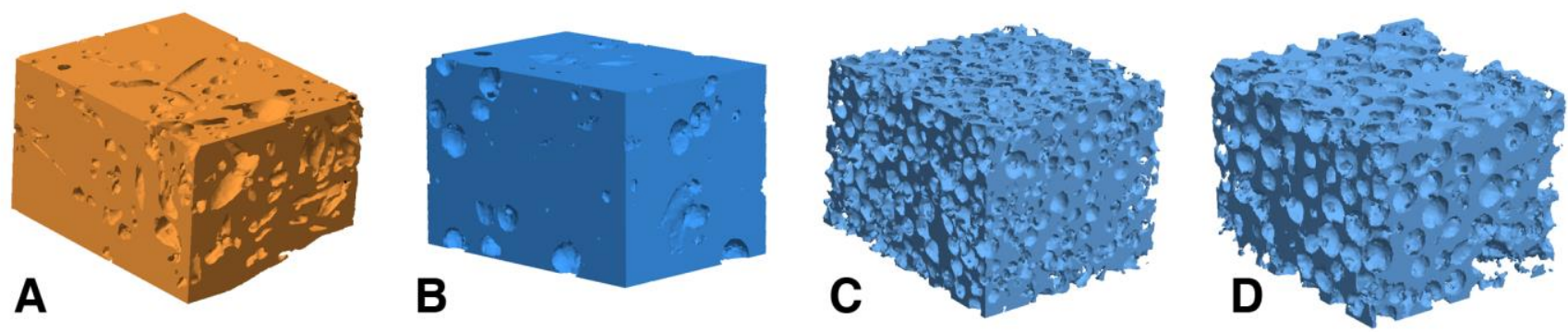

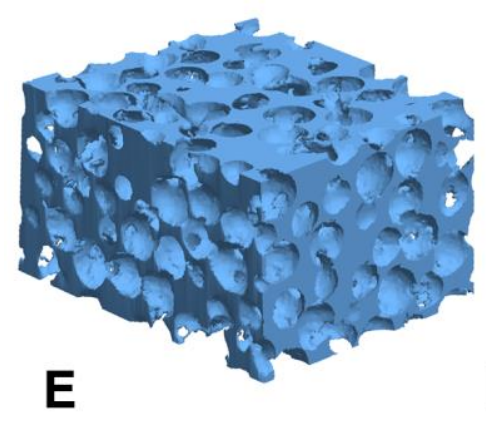

Fig. 1: 3D microCT analysis of different biomaterials used. A = "Angel's hairs" in PHEMA; B = PHEMA with urea beads; C to F: PHEMA with polystyrene beads with a 500, 800, 1100 and $1500 \mu \mathrm{m}$ diameter; $\mathrm{G}$ : $\mathrm{CaP}$ material; $\mathrm{H}$ : PHBV fibers. All 3D models are figured in pseudo-colors which are also used in graphs of figure 4.

Several porogens were used to prepare porous blocks of poly (2-hydroxethyl methacrylate) (PHEMA) as previously described [7, 23]. "Angel hairs", (i.e. filamentous fibers of glucose + sucrose) were prepared from sucrose/glucose as previously described [7]. Urea beads were obtained from Merck (France) and used as received. Polystyrene beads were prepared by the emulsion method as previously described [23]. Polystyrene beads were sieved to obtain homogeneous populations of 500, 800, 1100 and $1500 \mu \mathrm{m}$ in diameter.

Briefly, porous blocks of PHEMA were prepared by pouring the accelerated and initiated monomer into polyethylene molds (Peel-a-Way embedding systems, Polysciences, Warrington, PA, USA) containing the porogen. The different types of porous blocks were prepared by placing $1 \mathrm{~g}$ of porogen in the mold and filling up the mold with $25 \mathrm{ml}$ of HEMA. The accelerated and initiated HEMA contained $0.125 \%$ $(\mathrm{w} / \mathrm{v})$ of benzoyl peroxide and N,N-dimethyl paratoluidine at a final concentration of $0.3 \%$. The polymerization process was carefully checked until the gelling phase was obtained at room temperature. During this step, the porogens were gently homogenized and special care was taken to avoid the entrapment of air bubbles. Polymerization was achieved at $4^{\circ} \mathrm{C}$ in a flatbottomed flask that had been previously purged with nitrogen. Blocks of polymer containing "angel's hairs"

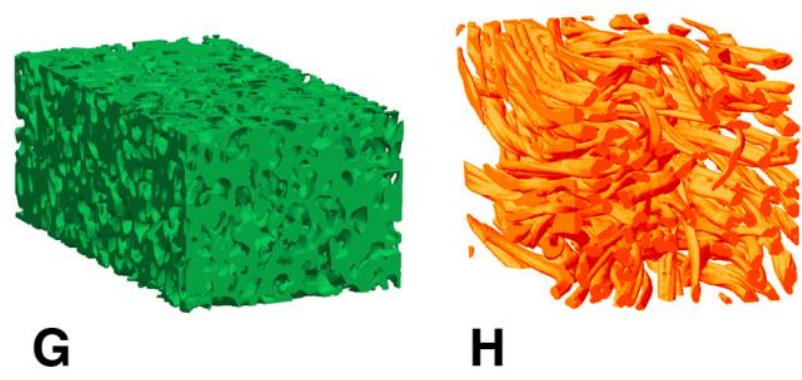

or urea were transferred in screw-capped bottles containing distilled water and placed on a continuous rotating agitator. Blocks containing the polystyrene beads were similarly transferred to dichloromethane (a solvent for polystyrene and a non-solvent for PHEMA). When all the porogen had dissolved (as checked by trans-illumination), the blocks were dried in an oven at $40^{\circ} \mathrm{C}$ for 3 days.

\subsection{2- Filamentous polymer}

Filaments

of a polyhydroxybutyrate/polyhydroxyvalerate polymer (PHBV) were prepared as followed: PHBV powder was purchased from Good fellow SARL (France) and used without any purification. PHBV fibers were prepared by a coagulation-precipitation in a non-solvent bath using a $20 \%$ (w/v) chloroform solution. Briefly, a 20\% PHBV chloroform solution was obtained by dissolving, under stirring at $70^{\circ} \mathrm{C}, 4 \mathrm{~g}$ of polymer powder in $20 \mathrm{~mL}$ chloroform. The polymer solution was carefully poured from a $5 \mathrm{~mL}$ syringe into a $1 \mathrm{~L}$ ethanol bath resulting in the formation of PHBV fibers. The fibers were collected from the bath after 5 minutes and air dried for $48 \mathrm{~h}$. They were inserted in $5 \mathrm{~mm}$ polyethylene test tubes.

\subsection{3) Calcium-phosphate porous material $(\mathrm{CaP})$}

The synthesis of a calcium deficient apatite $(\mathrm{Ca} / \mathrm{P}=1.60)$ was completed by alkaline hydrolysis of dicalcium phosphate dehydrated (DCPD, Merck, France) [24]. 

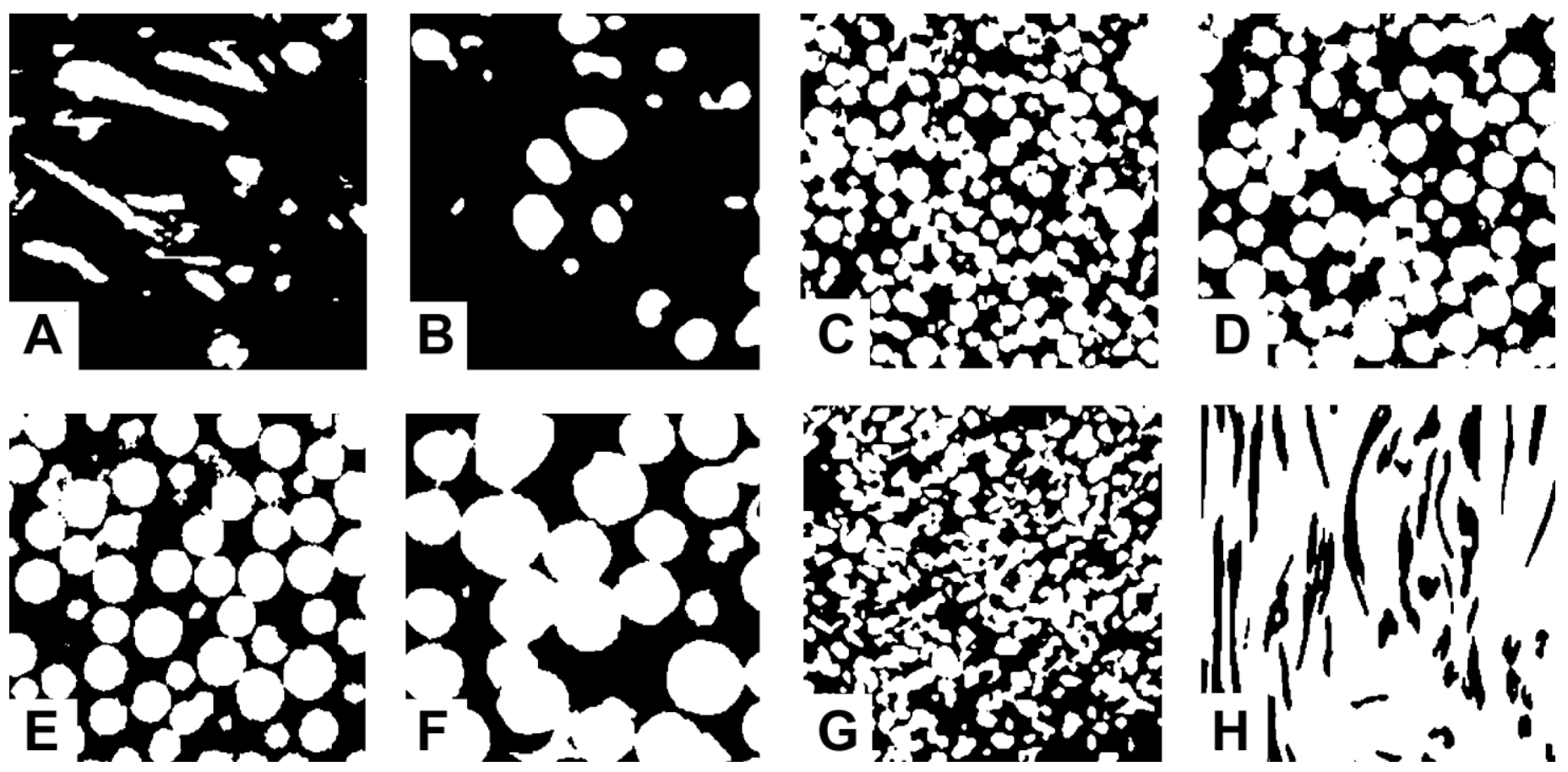

Fig. 2: The corresponding binarized 2D sections of biomaterials appearing in figure 1 . The material appears as black pixels and porosity as white pixels.

Crystalline sucrose and ammonium carbonate (Merck) were used as porogen and mechanically sieved (503 502 Sieve, Fristch Laborgerätebau, Germany) on 710 and $450 \mu \mathrm{m}$ sievers for $20 \mathrm{~min}$ to collect the intermediate granular fraction. The apatite powder $(31.6 \mathrm{~g})$ was mixed with $\left(\mathrm{NH}_{4}\right)_{2} \mathrm{CO}_{3}$ particles $(12.6 \mathrm{~g})$ and sucrose crystals $(13.3 \mathrm{~g})$ and introduced in an elastomer mold under vacuum, then the mold was transferred into a high-pressure chamber containing water and subjected to isostatic compression under $150 \mathrm{MPa}$ during $2 \mathrm{~min}$. The resulting compressed blocks were sintered in a controlled-temperature furnace (Vecstar, Eurotherm, Switzerland) according to the following process: the temperature was first raised to $60^{\circ} \mathrm{C}\left(2^{\circ} \mathrm{C} \mathrm{min}^{-1}\right)$ for 240 $\min$, then to $560^{\circ} \mathrm{C}\left(2^{\circ} \mathrm{C} \mathrm{min}^{-1}\right)$ for $300 \mathrm{~min}$ and then to $1050^{\circ} \mathrm{C}\left(5^{\circ} \mathrm{C} \mathrm{min}^{-1}\right)$ for $300 \mathrm{~min}$. Then, the resulting blocks were cooled down to room temperature $\left(5^{\circ} \mathrm{C}\right.$ $\left.\min ^{-1}\right)$.

\section{$2.2 \mathrm{X}$-ray microcomputed tomography (microCT)}

The blocks were fixed on brass stubs and analyzed with a Skyscan 1172 X-ray computed microtomograph (Bruker MicroCT, Kontich, Belgium). They were examined at a magnification of $\times 15.36$ (a pixel corresponding to $20 \mu \mathrm{m}$ ) with the cone beam mode at $80 \mathrm{kV}, 100 \mu \mathrm{A}$ with no aluminum filter and a $0.25^{\circ}$ rotation angle was applied at each step. Briefly, serial section images of the block were acquired and stored in

the *.bmp format. After interactive segmentation, the 3D models were constructed from the stack with a surface-rendering program (Ant, release 2.5.0.2, Skyscan). The fractional amount of the porosity (Po.V/V, in \%), the mean thickness of the biomaterial profiles between the pores (Mat.Th, in $\mu \mathrm{m}$ ) were determined by the CTAn software (release 1.11.10.0, Skyscan).

For applying the image analysis software, 2D sections were re-sliced from the 3D models: 2 sagittal images (separated by $200 \mu \mathrm{m}$ ) were obtained, 2 others section images were done in orthogonal plans. So, for each block, 4 images of size $270 \times 270$ pixels were obtained and binarized. Images were transferred to a Leica Quantimet Q550 (Leica, Nanterre, France) to be analyzed by lab-made software for the determination of the porosity characteristics. Then the images were transferred to a lab-made software written in Matlab (Math Works, Natick, Ma) release 7.10. The different types of materials used in this study appear on Figure 1 and binarized images of the sections on Figure 2.

\subsection{Image analysis}

The following parameters were measured on the Q550 Quantimet:

a) the Kolmogorov fractal dimension $\left(D_{K}\right)$ by the boxcounting and the Minkowski-Bouligand $\left(\mathrm{D}_{\mathrm{MB}}\right)$ dilatation methods were used as previously described 
[20]. Briefly $D_{K}$ was computed by overimposing grids of square boxes (with $\varepsilon$ pixels as side length) on the material's boundary and intersecting boxes were counted. The total number of boxes required to completely fill the boundaries reflected the perimeter with a scale ratio of $\varepsilon$. this step was repeated with $\varepsilon$ varying from 2 to 100 pixels and a $\log -\log$ graph (i.e. $\log [\mathrm{N}]$ against $\log [\varepsilon]$ ) was used to determine $\mathrm{D}_{\mathrm{K}}$ from the slope of the regression line. $\mathrm{D}_{\mathrm{MB}}$ was obtained by using a series of dilatations of the material's boundary and was repeated from 1 to 10 times; after each new dilatation $\varphi$, the material's border thickened and the surface area of the dilated image $A$ was measured. $\mathrm{D}_{\mathrm{KM}}$ was determined on the log-log graph from the slope of $\varphi / A(\varphi)$.

b) The Interconnectivity Index of the porosity (ICI) was determined by skeletonization of the pores $X$ (i.e., finding the centroids of maximal open discs included in the pore profiles) $[25,26]$. On the reconstructed skeleton $\mathrm{S}(X)$, the total number of nodes $\mathrm{N}$, node-tonode branches $(\mathrm{NN})$, node-to-free-end branches $\mathrm{NF}$ were determined. The number of 'trees' (T) was also obtained, a 'tree' being the structure composed of interconnected node(s) with node-to-node and/or nodeto-free-end branch. ICI of the porosity was then defined as:

\section{c) The star volumes}

$$
\mathrm{ICI}=(\mathrm{N} \times \mathrm{NN}) /(\mathrm{T} \times(\mathrm{NF}+1))
$$

The star volume of pores and materials were determined. Starting from a randomly placed seed in the porosity, one can project rays in all the directions of space [25]. The rays stop as soon as they meet a material boundary or edges of the block. This constitutes a kind of star and the measurement of the length of each ray of star is done. One sees that more disconnected will be the material, the more the length of the rays will be important. If a great number of stars is generated, small perforations are evidenced inside the material network. However, this method is very time consuming and the grid technique is preferred [27]: a series of grids was computed with parallel lines running with various angles running from 0 to $2 \pi$. Each grid was intersected with the image of the marrow cavities. This provided linear segments (called chords) superimposed on the pores. The cubed length of each chord $1_{0}^{3}$ was then computed with each grid, so that all directions from 0 to $360^{\circ}$ are explored very rapidly. The star volume was determined on the pores $\mathrm{V}_{\text {Pore }}^{*}$ (a high star volume indicates a highly fragmented material or the presence of larges pores). The other star volume $\left(\mathrm{V}_{\text {Mat }}^{*}\right)$ was determined by placing the seeds on the material itself to know the mean width separating the pores.

\subsection{Measurements of lacunarity and succolarity}

\section{a) Lacunarity}

We have used the "gliding box" method described by Allain and Cloitre $[16,28]$. A square box of side $\varepsilon$ was glided along all possible direction of the image. The total number of flooded pixels counted during this process was calculated. This procedure was repeated by gradually increasing the size of boxes. The total number of flooded pixels was defined by a mass distribution $n(M, \varepsilon)$. By dividing this number by the total number of boxes of size $\varepsilon$ :

$$
N(\varepsilon)=(S-\varepsilon+1)^{2}
$$

we obtained the probability distribution of $Q(M, \varepsilon)$, corresponding to the frequency of the number of occupation of a box of mass $M$ and size $\varepsilon$ :

$$
Q(M, \varepsilon)=n(M, \varepsilon) / N(\varepsilon)
$$

To analyze the properties of such a distribution, a common method is to study its statistical moments. Local lacunarity $(\delta)$ for a box side $\varepsilon$ is defined by the ratio between the second moment and the square of the first moment:

$$
\delta=\frac{\sum M^{2} \times Q(M, \varepsilon)}{\sum M \times Q(M, \varepsilon)^{2}}
$$

A $\log -\log$ graph of $\log (\delta)$ and $\log (\varepsilon)$ was used to determine $\mathrm{D}_{\delta}$ from the slop of the regression line

\section{b) Succolarity}

The approach for calculating succolarity $(\sigma)$ was provided by Melo and Conci using a box counting approach on a square image of side $n$ pixels [21]. Succolarity is calculated in one direction and then in the opposite direction: e.g. from left to right, from right to left, from top to bottom and from bottom to top (Figure 3 ). Briefly, in a first step, the image is flooded in a given direction ensuring that all black pixels of the first column are detected (the black pixels corresponding to the material, the white pixels to the pores). Then all the four connected black pixels are selected until an impenetrable mass of white pixels is encountered.

In a second step, the flooded image was analyzed using the sliding box method with the size of the box $t$ ranged from 2 to $n-1$ where $\mathrm{n}$ is the size of the image. The number of flooded pixels in the box $B\left(N_{\text {pixel }_{(B)}}\right)$ is determined as follows: 


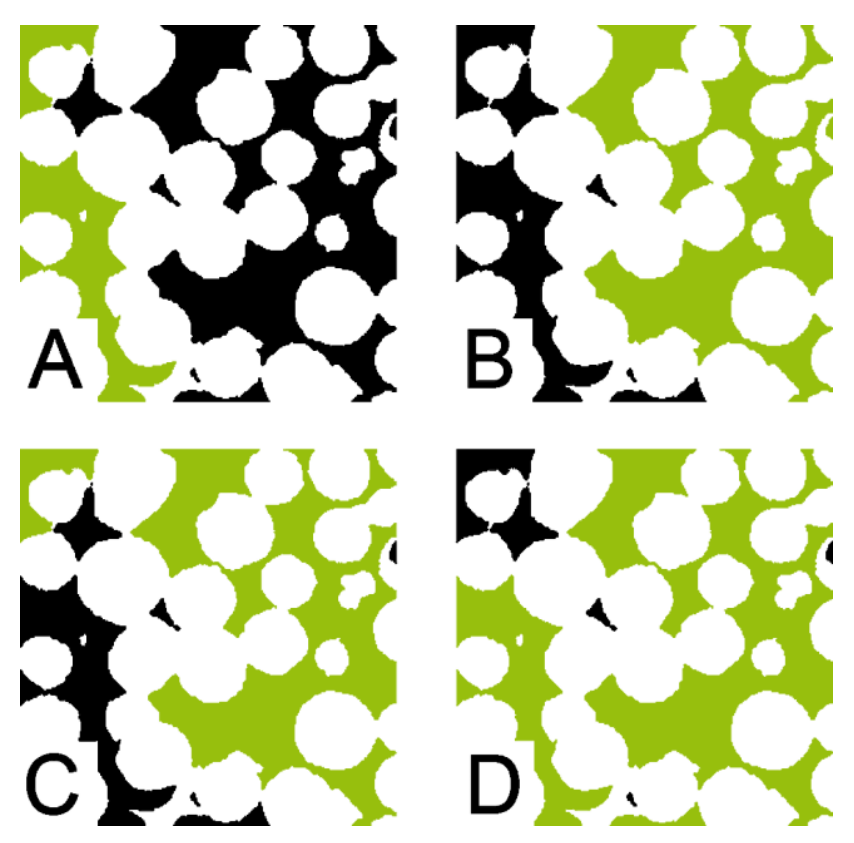

Fig. 3: Principle of succolarity $\square$ measurement by the flooding algorithm in the 4 directions. The black pixels of materials are flooded. A: from left to right; B: from right to left; C: from top to bottom; D: from bottom to top. The flooded pixels are in green.

$$
N_{\text {pixel }_{(B)}}=\frac{\sum \text { gray pixels }_{(\mathrm{B})}}{\text { Value of pixels }}
$$

In a third step, the occupation percentage of the box $\left.P O{ }_{B}\right)$ was calculated as the ratio of the number of flooded pixels and the square size of the box:

$$
P O_{(B)}=\frac{\sum N_{\text {pixel(B) }}}{\mathrm{t}^{2}}
$$

In a fourth step, the "pressure" $(P R)$ exerted on the boxes (by analogy to the liquid which has flooded the image) is stored in an array of pressures. The pressure increases from line to line (or column to column) along the direction of the flood.

On the first row or column: $\quad P R_{(B)}=\frac{1}{2} \times t_{(B)}$

On the other rows or columns: $P R_{(B)}=\left(\frac{1}{2}+l\right) \times t_{(B)}$

in which $l$ stands for the number of row or column.

Finally, succolarity for a given direction was calculated as:

$$
\sigma_{(\text {direction }, B)}=\frac{\sum_{t=1}^{n} P O_{(B)} \times P R_{(B)}}{\sum_{t=1}^{n} P R_{(B)}}
$$

Values were similarly computed in each direction and were averaged to calculate the global $\sigma$ of the image.

\subsection{Statistical analysis}

Statistical analysis was performed using the Systat statistical software release 13.0 (Systat Software Inc., San José, CA). All data were expressed as mean \pm standard error of the mean (SEM). Differences between groups were analyzed by a non-parametric ANOVA test (Kruskall-Wallis) with the Conover-Inman post-hoc test. Differences were considered significant when $\mathrm{p}<$ 0.05 .

\section{Results and discussion}

The 3D models of the different biomaterials appear on Fig.1, they are represented in pseudocolors which are also used in the graphs to improve clarity. The morphometric parameters of each type of biomaterial are reported in Table 1. MicroCT is a suitable method for measuring porosity. When compared to more classical methods such as Archimedes principle or mercury intrusion porosimetry, linear correlations have been reported with a $7 \%$ error $[29,30]$. These techniques were not used in the present study because PHEMA swell in water; furthermore, they are not applicable in case of non-connected porosity. We have chosen to illustrate the method on a series of different samples and comparing the results with morphometry with a 5\% error [11]. However, in all these materials, micro-porosity (which is observed in some types of materials prepared by sintering elementary particles) was not considered although it is known to strongly influence biomechanical properties [31]. Micro-porosity is typically in the range of $1-10 \mu \mathrm{m}$, and the mean size of the pixel used in this study was $20 \mu \mathrm{m}$. Because the present algorithms have been developed on 2D images, they could be applied to other images obtained by more precise devices such as nanotomograph or synchrotron which can image nanometric details.

The "angel's hairs" method provided an interconnected porosity in PHEMA as previously reported and evidenced on the 3D models (Fig. 1A). On the 2D sections, the profiles of the pores appeared either as separated filaments when cut longitudinally or as round/ellipsoidal profiles when sectioned transversally. The interconnectivity was observed occasionally when the profiles of two channels came in direct contact (Fig. $2 \mathrm{~A})$. However, porosity occupied only $\sim 20 \%$ of the material's volume. PHEMA materials prepared with beads of different diameters provided more or less 

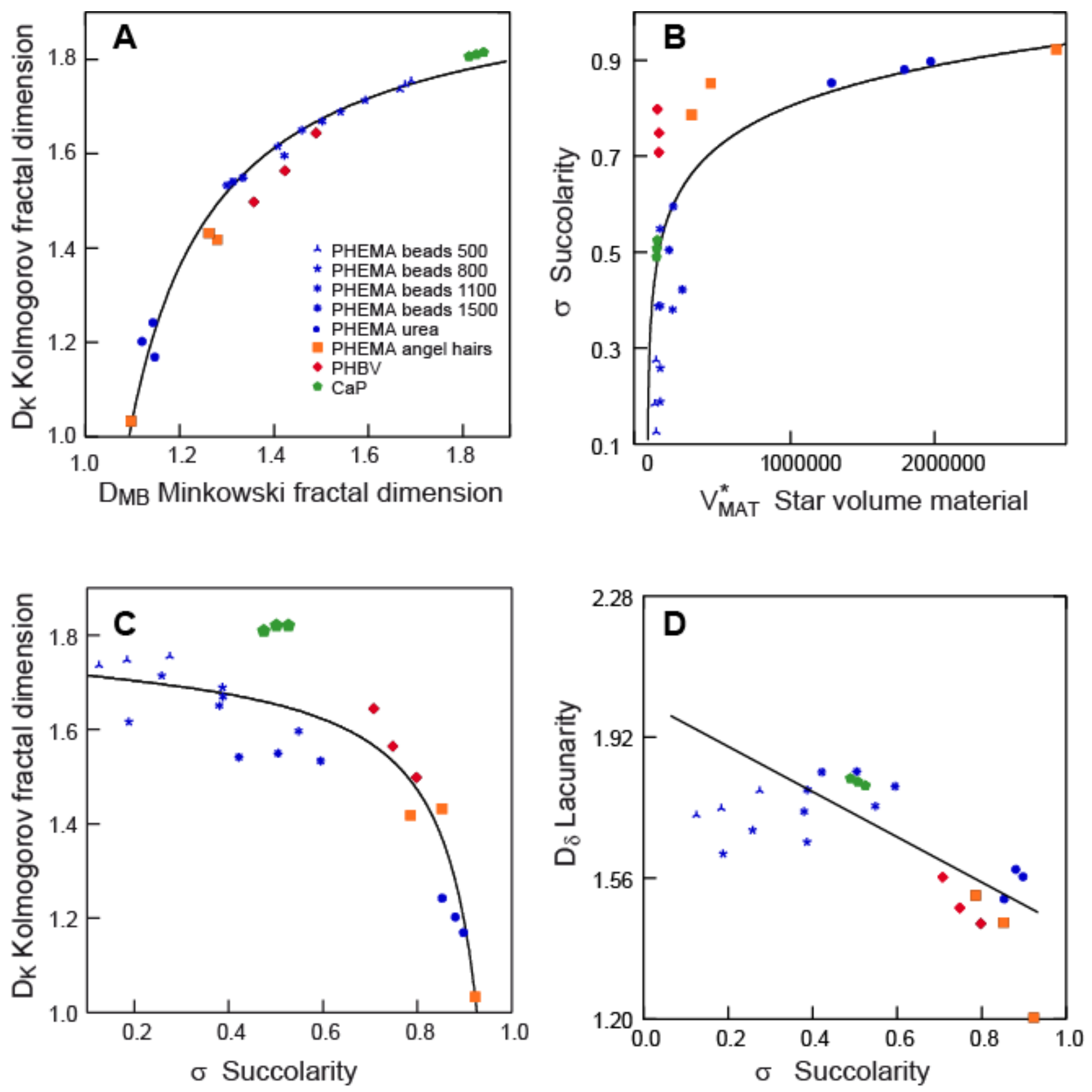

Fig. 4: Relationships between the different parameters characterizing pores and porosity. Log relationships between A: DMB and DK; B: between and $\square$; C: $\square$ and DK; D: linear correlation between succolarity $\square$ and lacunarity $\square$. On each graph, the different biomaterials are identified by specific symbols and colors which are the same than in figure 1

connected porosities (Fig 1B-F and Fig. 2B-F). The pores appeared spherical and interconnectivity occurred only when the beads were in contact tangentially. Urea

beads gave a non-connected porosity and the pores appeared scarcely distributed within the polymer (Fig. $1 \mathrm{~B}$ and $2 \mathrm{~B}$ ). The polystyrene beads provided highly porous blocks (Fig. 1C-F and 2C-F) but, surprisingly, the mean porosity Po.V/V did not differ significantly between the four types of materials. However, $V_{\text {Pore }}^{*}$ reflected well the mean size of the beads used as porogen. Reciprocally Mat.Th (reflecting the thickness 
of the material between the pores) increased as a function of the bead size used to prepare the blocks and interconnectivity, measured by ICI, decreased inversely to the porogen beads. Conversely, $\sigma$ and $V_{M a t}^{*}$ increased as a function of the bead diameter and the complexity of the porosity network decreased as evidenced by $D_{K}$ and $D_{M B}$ which decreased in parallel. The CaP material presented the highest porosity among the block materials with numerous very small pores (Fig.1G and 2G). However, ICI was low and evidenced a poor interconnectivity of the pores. In this last material, the pores appeared to provide a very complex pattern with the highest fractal dimensions $\delta, D_{K}$ and $\mathrm{D}_{\mathrm{MB}}$. The PHBV fibers were well separated (Fig. $1 \mathrm{H}$ and $2 \mathrm{H}$ ) and spaces between them were the highest of this series as evidenced by $\mathrm{V}_{\text {Pore }}^{*}$. These long fibers were thin and not connected as evidenced by ICI which reached very high values.

Po.V/V was poorly correlated with almost all parameters except $\mathrm{D}_{\mathrm{K}}$ and $\mathrm{D}_{\mathrm{MB}}$ (resp. $\mathrm{r}=0.53 ; \mathrm{p}=0.08$ and $\mathrm{r}=0.47 ; \mathrm{p}=0.02$ ), but the relationships only explained less than $25 \%$ of the variance. ICI and $\mathrm{V}_{\text {Pore }}^{*}$ were linearly correlated $(r=0.88 ; p<0.0001)$ confirming the interest of these parameters for the analysis of interconnectivity. $\mathrm{D}_{\mathrm{K}}$ and $\mathrm{D}_{\mathrm{MB}}$ were highly correlated with a logarithmic correlation $(\mathrm{y}=\mathrm{a}+\mathrm{b} /$ $\log (\mathrm{x})) \quad(\mathrm{r}=0.96 ; \mathrm{p}<0.0001)$ (Fig. 4A). The $\mathrm{CaP}$ material having the more complex structure presented the highest $D_{K}$ and $D_{M B}$ values. Succolarity of the materials (which reflects the degree of penetration of a liquid inside the material; i.e. the black pixels in Fig. 2) appears at the opposite of $\mathrm{D}_{\delta}, \mathrm{D}_{\mathrm{K}}$ and $\mathrm{D}_{\mathrm{MB}}$ fractal dimensions. $\sigma$ had the highest values in images where large territories of materials were present. When searching for correlations, a logarithmic relationship was observed between $\sigma$ and $V_{\text {Mat }}^{*}$ (Fig. 4B). Similarly, $\sigma$ appeared negatively correlated with $\mathrm{D}_{\mathrm{MBB}}(\mathrm{r}=-0.77$; $\mathrm{p}=0.0001)$ and $\mathrm{D}_{\mathrm{K}}(\mathrm{r}=-0.92 ; \mathrm{p}=0.00001)$ (Fig. 4C). A negative linear correlation was found between $\sigma$ and $\delta$ $(\mathrm{r}=-0.68 ; \mathrm{p}=0.0002)$ (Fig. 4B).

Non-linear relationships were observed between porosity Po.V/V and other parameters. This was previously reported for trabecular bone when considering its 3D microarchitecture vs. the bone volume (bone volume been equal to $100-\mathrm{Po} . \mathrm{V} / \mathrm{V}$ ) [25, 32, 33]. In this study, the different parameters used appear to provide more information about the porosity of these materials (e.g. on the homogeneity of the pores' size and interconnectivity). In the series of PHEMA blocks prepared with polystyrene beads varying over a wide range of diameters, the evolution of Euclidean (i.e. $\mathrm{V}_{\text {Pore }}^{*}$ ) and some fractal dimensions (e.g. lacunarity) were similar.

Succolarity represents the percolation of the material itself while the pores constituted the obstacles. In this study, the possibility to investigate $\sigma$ in a particular direction was not taken into account since the materials (excepted PHBV) had no preferential orientation; so the mean value of the 4 dimensions was used. In the PHEMA series with polystyrene beads, $\sigma$ regularly increased; it reached its maximum for PHEMA with urea beads that were loosely disposed and did not exhibit interconnectivity. Here again, the relationships of $\sigma$ with other descriptors were usually nonlinear. $\sigma$ and $\mathrm{D}_{\delta}$, on the other hand were linearly correlated.

\section{Conclusion}

New morphometric methods were used to better characterize the porosity of biomaterials. Connectivity of the pore was measured by computing the Interconnectivity index and the star volumes on $2 \mathrm{D}$ sections obtained by microCT. These parameters, based on Euclidean geometry, were refined by measuring the complexity of the pore size and their interconnectivity with measurements based on Fractal geometry (Kolmogorov and Minkowski-Bouligand fractal dimensions) and the newly described fractal parameters lacunarity and succolarity. Non-linear relationships exist between these descriptors of porosity and the amount of the materials constituting the pore throats. Fractal descriptors constitute a very promising approach in this field and should be used to better characterize porous materials. These parameters can be applied to non-homogeneous and anisotropic materials. These characteristics may help in designing new types of scaffolds to allow a better invasion of the grafted materials by vascular sprouts and progenitor cells.

\section{Acknowledgments}

This work was made possible by grants from Contrat Region Pays de la Loire: Bioregos2 program. Many thanks to Mr. Guillaume Mabilleau for reviewing the revised version of the manuscript and Mrs Lechat for secretarial assistance.

\section{Conflict of interest: none}




\section{References}

[1] B.D. Ratner, A.S. Hoffman, F.J. Schoen, J.E. Lemons, Biomaterial science: a multidisciplinary endeavor, in: B.D. Ratner, A.S. Hoffman, F.J. Schoen, J.E. Lemons (Eds.) Biomaterials science: an introduction to materials in medicine $2^{\text {nd }}$ Ed., Elsevier, Acad Press, 2004, pp. 1.

[2] S. Ban, J. Hasegawa, S. Maruno, Biomaterials, 12 (1991) 205.

[3] J.M. Anderson, G. Cook, B. Costerton, S.R. Hanson, A. Hensten-Pettersen, N. Jacobsen, R.J. Johnson, R.N. Mitchell, M. Pasmore, F.J. Schoen, M. Shirtliff, S. P., Host response to biomaterials and their evaluation. in: B.D. Ratner, F.J. Schoen, J.E. Lemons (Eds.) Biomaterials science: an introduction to materials in medicine $2^{\text {nd }}$ Ed., Elsevier, San Diego, 2004, pp. 293.

[4] R. Hernandez, S. Polizu, S. Turenne, L. Yahia, BioMedical Materials and Engineering, 12 (2002) 37.

[5] A.C. Jones, C.H. Arns, D.W. Hutmacher, B.K. Milthorpe, A.P. Sheppard, M.A. Knackstedt, Biomaterials, 30 (2009) 1440.

[6] S.S. Kohles, J.B. Roberts, Journal of Biomechanical Engineering, 124 (2002) 521.

[7] R. Filmon, N. Retailleau-Gaborit, F. Grizon, M. Galloyer, C. Cincu, M.F. Baslé, D. Chappard, Journal of Biomaterials Science, Polymer Edition, 13 (2002) 1105.

[8] M. Klein, H. Goetz, S. Pazen, B. Al-Nawas, W. Wagner, H. Duschner, Clinical Oral Implants Research, 20 (2009) 67.

[9] Y. Hiu-Yan, Q. Ling, L. Kwong-Man, Z. Ming, L. Kwok-Sui, C.J. Chun-yiu, J Biomed Mater Res B Appl Biomater, 75 (2005) 234.

[10] K. Schladitz, Journal of Microscopy, 243 (2011) 111.

[11] D. Chappard, N. Retailleau-Gaborit, E. Legrand, M.F. Baslé, M. Audran, Journal of Bone and Mineral Research, 20 (2005) 1177.

[12] B. Mandelbrot, The fractal geometry of nature., Freeman, W.H., N.Y., 1977.

[13] A. Block, W. von Bloh, H.J. Schellnhuber, Physical Review A, 42 (1990) 1869.

[14] T.G. Smith, Jr., G.D. Lange, W.B. Marks, Journal of Neuroscience Methods, 69 (1996) 123.

[15] P. Grassberger, Journal of Statistical Physics, 26 (1981) 173.

[16] R.H.C. de Melo, in, Federal university of Fluminense (Brazil), Fluminense, 2007, pp. Ph.D. Link: http://www.ic.uff.br/ rmelo/msc_thesis.htm.

[17] R.H.C. de Melo, E.A. Vieira, A. Conci, Comparing two approaches to compute Lacunarity of mammograms., in: 13th international conference on systems, signal and image processing and semantic multimodal analysis of digital media (IWSSIP 2006), IEEE signal processing society Budapest, 2006, pp. 299.

[18] J.L. Levy Vehel, Using fractal and morphological criteria for automatic classification of lung diseases., in: SPIE (Ed.) Conference on Visual Communications and Image Processing, Philadelphia; PA (USA), 1989, pp. 903.

[19] S. Gilmore, R. Hofmann-Wellenhof, J. Muir, H.P. Soyer, PLoS One, 4 (2009) e7449.

[20] D. Chappard, E. Legrand, B. Haettich, G. Chales, B. Auvinet, J.P. Eschard, J.P. Hamelin, M.F. Baslé, M. Audran, Journal of Pathology, 195 (2001) 515.

[21] R.H.C. de Melo, A. Conci, Telecommunication Systems, (2011) DOI 10.1007/s11235.

[22] S.S. Hassan, P.P. Choudhury, D. Sagar, S. Chakraborty, R. Guha, A. Goswami, in: IEEE/ACM Transactions on Computational Biology and Bioinformatics, IEEE, 2011, pp. 1.

[23] I.C. Stancu, P. Layrolle, H. Libouban, R. Filmon, G. Legeay, C. Cincu, M.F. Baslé, D. Chappard, Journal of Optoelectronics and Advanced Materials, 9 (2007) 2125.

[24] J.M. Bouler, R.Z. LeGeros, G. Daculsi, Journal of Bone and Mineral Research A, 51 (2000) 680.

[25] D. Chappard, E. Legrand, C. Pascaretti, M.F. Baslé, M. Audran, Microscopy Research and Technique, 45 (1999) 303.

[26] H.M. Le, R.E. Holmes, E. Shors, D.A. Rosenstein, Acta Stereologica, 11S1 (1992) 267.

[27] P. Levitz, D. Tchoubar, Journal de Physique I, 2 (1992) 771.

[28] C. Allain, M. Cloitre, Physical review A, 44 (1991) A3552.

[29] J.R. Jones, G. Poologasundarampillai, R.C. Atwood, D. Bernard, P.D. Lee, Biomaterials, 28 (2007) 1404.

[30] S. Truscello, G. Kerckhofs, S. Van Bael, G. Pyka, J. Schrooten, H. Van Oosterwyck, Acta Biomaterialia, 8 (2012) 1648.

[31] W. Niu, S. Gill, H. Dong, C. Bai, Computational Materials Science, 50 (2010) 172.

[32] D. Chappard, E. Legrand, M.F. Baslé, P. Fromont, J.L. Racineux, A. Rebel, M. Audran, Journal of Bone and Mineral Research, 11 (1996) 676.

[33] J.S. Thomsen, E.N. Ebbesen, L. Mosekilde, Bone, 22 (1998) 153. 